\title{
The Assessment of Causes and Consequences of Medical Staff Absenteeism and Turnover in Arba Minch General Hospital
}

\author{
Tekle Dula ${ }^{1} \quad$ Gudata Abara ${ }^{2}$ Dr. P.A.K. Reddy ${ }^{3}$ \\ 1.Trade and Industry Department, Gamo Gofa Zone, Arbaminch, Southern Ethiopia \\ 2.Wollega University, College of Business and Economics, Department of Accounting and Finance, Ethiopia \\ 3.Wollo University, College of Business and Economics, Department of Accounting and Finance, Ethiopia
}

\begin{abstract}
The purpose of this study is to assess the causes of medical staff absenteeism and turnover in case of Arbaminch General Hospital. In addition, it explores the consquences/ impact of absenteeism and trunover on patients care,workload on medical staff and reputation on Arbaminch General Hospital. To this end, the study employed a descriptive, correlation and regession analysis. Data was collected using closed ended structured questionnaires by applying Likert scale which were filled by full time medical staff $(\mathrm{N}=50)$. The findings indicate that demographic factors such as marital status, working experiences, educational level and have significant negative correlation with absenteeism and turnover. Organizational factors such as working condition and work load have positive significant correlation with medical staff absenteeism and turnover. In contrast, all studied organizational factors such as compensation/ incentive program, promotional opportunities, managerial style, training and development and career development are significantly negatively correlated with both absenteeism and turnover. The findings also indicated that medical staff absenteeism and turnover had consequences on patient care, increasing workload on existing staff, and bad reputation for hospital. Furthermore, both absenteeism and turnover have resulted in demoralization of existing medical staff at Arbaminch General Hospital.
\end{abstract}

Keywords: Demographic Variables, Job Factors, Organizational Factors, Patient Care, Demoralization, Absenteeism, Turnover

DOI: $10.7176 / \mathrm{JHMN} / 58-04$

\section{INTRODUCTION}

Employee turnover is expensive from the view of the organization. Voluntary quits which represents mass departure of people of human capital investment from organizations and the subsequent replacement process entails manifold costs to the organizations. These replacement costs include for example, search of the external labor market for a possible substitute, selection between competing substitutes, induction of the chosen substitute, and formal and informal training of the substitute until he or she attains performance levels equivalent to the individual who quit. Addition to these replacement costs, output would be affected to some extend or output would be maintained at the cost of overtime payment (John 2000). According to Hacker (1999) when an employee leaves, other employees who were sociable with the leaver may feel distressed. If leavers are valuable co-workers, and/or if the work group is cohesive, turnover can have a negative effect on those remaining.

\section{Statement of the problem}

From the national and international literature, it is evident that medical staff absenteeism and turnover is a problematic issue. The study will observe tendency to medical staff absenteeism and turnover on governmental hospital. Absenteeism and turnover are obvious among staff and the factors that are playing in a Government Hospital of Arbaminch have not been investigated and documented formally. The study is employed to assess the causes and impact of absenteeism and turnover in Arbaminch general Hospital. The specific reasons for absenteeism and turnover of the medical staff in this Government Hospital are not assessed and unclear. The causes could be followings. First, demographic factors such as age, gender, educational status, marital status, tenure. Second, job related factors such as work load, working conditions, and routine work. Third, organizational factors including incentives programs, promotional opportunities, managerial style, training and development. Both the medical staff and the patients in this hospital experience the consequences of poorly managed absenteeism and turnover.

The staff turnover and absenteeism have the following impacts on hospital performance:

First, existing medical staff will have increased workload and get demoralized if absenteeism and turnover is frequent.

Second, the patients care service quality is also impacted if absenteeism and turnover.

> Generally, organization has planned to serve the number of patients daily based on the employees' number. Absenteeism and Losing the critical employees (qualified) and experienced medical staff professionals' leads to negatively affect the productivity (effectiveness) of healthcare organization in a various ways, such as demoralization of existing staff, decrease quality of patient care. 
In order to solve the aforementioned problems the following questions are raised:

$>$ What are the causes of absenteeism and turnover in Arbaminch general hospital?

$>$ What are the consequences of medical staff absenteeism and turnover in the hospital under consideration?

$>$ To what extent absenteeism and turnover affect patients care?

To what extent

\section{Objectives of the study}

The general objective of the study is to assess the causes and consequences of medical staff absenteeism and turnover in Arbaminch General Hospital.

To attain the above general objective, there are specific objectives that need to be studied in the case of Arbaminch General Hospital. These are as follows:

$>$ To assess causes of absenteeism and turnover in Arbaminch general hospital.

$>$ To examine consequences of absenteeism and turnover on hospital performance.

$>$ To analyze the impact of absenteeism and turnover on patient care.

$>$ To foresee the impact of workplace absenteeism and turnover on morale of existing medical staffs.

$>$ Provide possible recommendation that can cause work places absenteeism and turnover

\section{Significance of the Study}

Governmental and public sector organizations success can be measured mainly through delivery of quality service to their beneficiaries. This can be achieved through well formulated plans and programs, allocation of resources, assignment and retention of committed and competent staffs. Therefore, the researcher is highly aware of that the results of this study have the following significance for different bodies:

- It will help public hospital to understand the causes and impact of absenteeism and turnover affects organizational performances. This helps the management to create awareness on absenteeism and turnover causes and consequences.

- The researcher will get knowledge and understanding regarding assessing the absenteeism and turnover employees.

- It serves as base for interested researchers as a reference on the issue in conducting future and detail study in the area.

- Furthermore, the study will put contribution for University's research and development purpose

- The study will certain be a key indicator for sustainability of the staff with judicious welfare of the all stake holders toward betterment and competitiveness' of medical services in Ethiopia.

\section{MATERIALS AND METHODS}

The population for this study is permanent medical professionals working in the Arbaminch General Hospital totally 229. This includes all categories of medical staff namely specialist, general practitioner, health officers, all nurses' pharmacist, laboratory technology and assistant, sanitary, optical, Anastasia and X-ray, enrolled in hospital. Out of this, total number of female is $46.67 \%$ (100) and male is $53.33 \%(127)$. Of this total population, the sample size selected for this study is $20 \%$ (50) to provide the required information. The sampling was compiled by means of a stratifying random sampling techniques this is due to the fact that each group of medical staffs have different professional field of studied/level of education and areas of specialization which help to collect data from them as per their views, knowledge and to what extent absenteeism and turnover affects the operational activities of the Hospital. The strata of total selected sample size are $20 \%$ specialist, $20 \%$ general practitioner, 20\% health officer, 20\% all nurses, 20\% pharmacist technology and assistant, 20\% laboratory technology and assistant, 20\% optical 20\% anesthesia and 20\% X-ray with totally size of 50 in number those who are currently acting on their job. To do so the questionnaire paper were given to employee and fulfilled the necessary information. Data collection was made using appropriate methods to meet the specific objectives of the study. In the first phase of the study, the survey will be conducted on the employees through the use of close ended questionnaires. The material is in a Likert Scale form which gives the details to the researcher on the perception of the employees on absenteeism and turnover to provide the findings of the study. It was used to obtain their view about the causes and consequences of absenteeism and turnover on organizational performance. Descriptive statistics and inferential Statistical such as correlation and regression analysis were used for analysis. In addition, program of Statistical Packaging for Social Sciences (SPSS) was also used. 


\section{RESULTS AND DISCUSSION}

Relationship analysis of medical staff absenteeism and turnover in Arbaminch General Hospital The correlation analysis of Demographic factors with absenteeism and turnover

Table 1. The Pearson correlation matrix analysis between demographic variables with medical staff's absenteeism and turnover

Independent variables
Gender of respondent
Marital status of respondent
Level of educational qualification
Age of respondent
Working experiences of respondent

\begin{tabular}{llll}
\hline $\begin{array}{l}\text { Dependent variables } \\
\text { Absenteeism }\end{array}$ & \multicolumn{2}{l}{ Turnover } \\
$\mathrm{r}$ & $\mathrm{p}$ & $\mathrm{r}$ & $\mathrm{p}$ \\
.155 & .281 & .103 & .476 \\
$-.396^{* *}$ & .004 & $-.706^{* *}$ & .000 \\
$-.386^{* *}$ & .006 & $-.462^{* *}$ & .001 \\
$-.323^{*}$ & .022 & $-.433^{* *}$ & .002 \\
$-.294^{*}$ & .038 & $-.496^{* *}$ & .002 \\
\hline
\end{tabular}

From the above table 1, correlation analysis, where $r$ is to show the relationship between gender and absenteeism at Pearson correlation of $r=0.155$. Also it show the relationship between gender and turnover indicated by the Pearson correlation $\mathrm{r}=0.103$ at ( $\mathrm{p}$ value .281 and .476 ) for both absenteeism and turnover respectively where $\mathrm{p}$ value is $>$ at significant level.05, therefore gender has insignificant relationship for absenteeism and turnover among medical staff in Arbaminch General Hospital.

Based on above correlation table 1 as the results shows the relationship between marital status in organization and absenteeism at Pearson correlation of $r=-.396^{* *}$ where $p$ value was .004 which is less than the significant level of .05. This indicated that there is negative relationship between marital status and absenteeism. In addition, the correlation results indicated that at Pearson correlation $\left(r=-.706^{* *} \mathrm{p}\right.$ values at .000$)$ for marital status and turnover where $\mathrm{p}$ value is less than significant level.01, which means there is strong negative relationship between marital status and turnover among medical staff in Arbaminch General Hospital. The implication of the above data indicates that the marital status of medical staffs is strong relationship for absenteeism and turnover. This means that as one employee married he/she is attached to the organization and interested to work for the hospital to pursue the organizational goals.

Therefore the finding indicated that as married employee less sensitive to absenteeism and turnover than single. If married employees are more, the level of absenteeism and turnover among medical staff tend to decreases.

From the above table 1 the correlation matrix analysis results shows the relationship between level of educational qualification and absenteeism at Pearson correlation of $\mathrm{r}=-.386^{* *}$. It Also shows the relationship between level of educational qualification and turnover indicated by the Pearson correlation $r=-.462^{* *}$ at $(p$ value.006 and .001) for level of education with absenteeism and turnover respectively where $\mathrm{p}$ value is less than significant level.05. Therefore, the level of educational qualification has significant negative relationship with absenteeism since $\mathrm{p}$ value is less than significant level .01. There is also strong negative significant relationship between level of educational qualification and turnover of medical staff in Arbaminch General Hospital this means as level of educational qualification increases the tendency to be absent and tend to leave the organization decreases.

From the above table 1 the correlation matrix analysis results shows the relationship between Age and absenteeism at Pearson correlation of $\mathrm{r}=-.323^{*}$ It Also shows the relationship between Age and turnover indicated by the Pearson correlation $\mathrm{r}-.433^{* *}$ ( $\mathrm{p}$ value 0.022 and .002 ) for age with absenteeism and turnover respectively where $\mathrm{p}$ value is less than significant level.05. Therefore, the Age has significant negative relationship with absenteeism since $\mathrm{p}$ value is less than significant level .01 . There is also strong negative significant relationship between Age and turnover of medical staff in Arbaminch General Hospital. Hence as age increases the tendency to be absent and tend to leave the organization decreases.

The correlation matrix analysis between working experience in organization with medical staff absenteeism and turnover based on above correlation table 1 the results shows the relationship between working experiences in organization and absenteeism at Pearson correlation of $r=-.294 *$ where $\mathrm{p}$ value was 0.038 which is less than the significant level of .05 . This indicated that there is negative relationship between working experience and absenteeism. In addition, the correlation results indicated that at Pearson correlation $\left(\mathrm{r}=-.496^{* *}, \mathrm{p}\right.$ values at .002 ) for working experience and turnover where $\mathrm{p}$ value is less than significant level.01, which means there is strong negative relationship between working experiences and turnover among medical staff in Arbaminch General Hospital. Therefore the finding indicated that as working experience/ services year increases, the level of absenteeism and turnover among medical staff tend to decreases. Based on finding in general all demographic variables except gender have negative significant relationship with both absenteeism and turnover in Arbaminch General Hospital. 
Relationship between absenteeism and turnover with job related variables (working condition, workload and routine work.

Table 2. Pearson correlation analysis results of relationship between job factors with absenteeism and turnover.

Demographic variables

Working condition on hospital

Workload on medical staff

Routine work for staff

\begin{tabular}{llll}
\hline \multicolumn{2}{l}{ Dependent variables } & & \\
Absenteeism & & Turnover & \\
$\mathrm{r}$ & $\mathrm{p}$ & $\mathrm{r}$ & $\mathrm{p}$ \\
$.337^{*}$ & .017 & $.532^{* *}$ & .000 \\
$.662^{* *}$ & .000 & $.594^{* * *}$ & .000 \\
.165 & .252 & .017 & .909 \\
\hline
\end{tabular}

*. Correlation is significant at the 0.05 level (2-tailed).

**. Correlation is significant at the 0.01 level (2-tailed).

Based on above correlation table 2 as the results shows relationship between working condition and absenteeism at Pearson correlation of $r=.337^{*}$ where $\mathrm{p}$ value was .017 which is less than the significant level of .05 . This indicated that there is positive relationship between working condition and absenteeism. In addition, the correlation results indicated that at Pearson correlation $\left(\mathrm{r}=.532^{* *}, \mathrm{p}\right.$ values at .000$)$ for working condition and turnover where $\mathrm{p}$ value is less than significant level.01, which means there is strong positive relationship between working condition and turnover for medical staff in Arbaminch General Hospital. Therefore the finding indicated that as working condition being unsafe and, poor which exposes professional be absent from work and tends to leave organization.

From the above table 2 the correlation matrix analysis results show the relationship between workload and absenteeism at Pearson correlation of r. $662^{* *}$. It Also shows the relationship between level of workload and turnover indicated by the Pearson correlation $\mathrm{r}=.594^{* * *}$ at ( $\mathrm{p}$ value.000 and .000$)$ for workload with absenteeism and turnover respectively where $\mathrm{p}$ value is less than significant level.01. Therefore, workload has significant strong positive relationship with absenteeism since $p$ value is less than significant level .01 . There is also strong positive significant relationship between workload and turnover of medical staff in Arbaminch General Hospital i.e. medical staff is absent from work and prepare to leave organization. Also the correlation matrix analysis results from the above table 2 show the relationship between routine work and absenteeism at Pearson correlation of $\mathrm{r}=.165$ in addition to show the relationship between routine work and turnover indicated by the Pearson correlation $r=.017$ at ( $\mathrm{p}$ value .252 and 0.909 ) for both absenteeism and turnover with routine work respectively where $p$ value is greater than at $p$ significant level.05 value. Therefore the routine work has insignificant relationship both absenteeism and turnover in organization. So it is not related to be absent and leaving from organization.

Based on finding all job factors/work related variable except routine work have positive significant relationship with both absenteeism and turnover in Arbaminch General Hospital.

Relation between organizational factors with absenteeism and turnover

Table 3. Pearson correlation analysis of the relationship between organizational factors with medical staff's absenteeism and turnover

\section{Independent variables}

Incentive program for medical staff

Promotional opportunity for

medical staff

Managerial style to medical staff

Training and development for medical staff

Career development for medical staff

\begin{tabular}{llll}
\hline \multicolumn{2}{l}{ Dependent variables } & \multicolumn{2}{l}{ Turnover } \\
\multicolumn{2}{c}{ Absenteeism } & \multicolumn{1}{l}{} \\
$\mathrm{R}$ & $\mathrm{p}$ & $\mathrm{r}$ & $\mathrm{P}$ \\
$-.352^{* *}$ & 0.020 & $-.480^{* *}$ & 0.000 \\
$-.250^{*}$ & .0 .040 & $-.497^{* *}$ & 0.000 \\
& & & \\
$-.316^{*}$ & $0.025^{*}$ & $-.474^{* *}$ & 0.000 \\
$-.505^{* *}$ & 0.000 & $-.597^{* *}$ & .000 \\
$-.519^{* *}$ & .000 & $-.571^{* *}$ & .000 \\
\hline
\end{tabular}

**. Correlation is significant at the 0.01 level (2-tailed).

*. Correlation is significant at the 0.05 level (2-tailed).

From the above table 3 the correlation matrix analysis results shows the relationship between incentive program/compensation and absenteeism at Pearson correlation of $\mathrm{r}=-.352^{* *}$ it Also shows the relationship between incentive program/compensation and turnover indicated by the Pearson correlation $r=-.480^{* *}(p$ value.020 and .000) for incentive program/compensation with absenteeism and turnover respectively where for $p$ value is less than significant level.05. Therefore, the incentive program/compensation has significant negative relationship with absenteeism since $\mathrm{p}$ value is less than significant level .01. There is also strong negative significant relationship between incentive program/compensation and turnover of medical staff in Arbaminch General Hospital thus turnover is more negatively related incentive program/compensation than absenteeism in organization. 
From the above table 3 , the correlation matrix analysis results shows the relationship between Promotional opportunity for medical staff and absenteeism at Pearson correlation of $\mathrm{r}=-.250^{* *}$. It also shows the relationship between promotional opportunity of medical staff and turnover indicated by the Pearson correlation $\mathrm{r}=-.497^{* *}$ and the $\mathrm{p}$ value ( $\mathrm{p}$ value.0.040 and .000 ) of promotional opportunity for medical staff with absenteeism and turnover respectively whereas $\mathrm{p}$ value is less than significant level.05 with absenteeism and less than 0.01 with turnover. Therefore, the promotional opportunity for medical staff is negative significant relationship with absenteeism since $\mathrm{p}$ value is less than significant level .05. There is also strong negative significant relationship between promotional opportunity for medical staff and turnover of medical staff in Arbaminch General Hospital because $\mathrm{p}$ value is less than significant level .01 i.e. turnover is more negatively related promotional opportunity than absenteeism in the hospital.

Based on above correlation table 3 as the results shows the relationship between managerial style to medical staff and absenteeism at Pearson correlation of $r-316$ where $p$ value was 0.025 which is less than the significant level of $\mathrm{p}$ value .05 . This indicated that there is negative relationship between managerial style and absenteeism. In addition, the correlation results indicated that at Pearson correlation $\left(\mathrm{r}-.474^{* *} \mathrm{p}\right.$ values at .000$)$ for managerial style and turnover where $\mathrm{p}$ value is less than significant level.01 this means there is strong negative relationship between managerial style s and turnover of medical staff in Arbaminch General Hospital. Therefore the finding indicated that the relationship between managerial style with absenteeism and turnover are inversely related and medical staff is more sensitive to ward managerial style. Also it was explained by researcher such as (Gerber, 1998) found that Nurse Managers need to motivate their nursing staff by using power, but misuse of power adversely lowers nurse's morale, which in turn could lead to their absenteeism on other hand also if relationship medical staff means participatory Managers should foster initiative and responsibility by allowing staff to participate in decision making. This boosts staff confidence, increases self-efficacy and therefore reduces absenteeism (Laschinger et al.1997) in contrast the relationship between managers to medical staff is negative means it is not participatory on decision making it may lead medical staffs not retain and absent from work.

Based on above correlation table 3.3 as the results shows the relationship between training and development for medical staff and absenteeism at Pearson correlation of $r=-.505^{*}$ where $\mathrm{p}$ value was 0.000 which is less than the significant level of .01. This indicated that there is strong negative relationship between training and development for medical staff and absenteeism. In addition, the correlation results indicated that at Pearson correlation $\left(\mathrm{r}=-.597^{* *}, \mathrm{p}\right.$ values at .002$)$ for training and development for medical staff and turnover where $\mathrm{p}$ value is less than significant level.01, which means there is strong negative relationship between training and development for medical staff and turnover of medical staff in Arbaminch General Hospital. Therefore the finding indicated that as training and development is important points that inversely relate to absence and retention to medical staff on Arbaminch General Hospital.

Also correlation results indicated on table 3 the relationship between career development and absenteeism with $r=-.519^{*} \mathrm{p}=-.000$ with results indicate that where $\mathrm{p}$ value is less than at significant value /level 0.01 Hence career development has significant negative relationship with absenteeism .In addition, there is based on the correlation results, the relationship between career development and turnover at Pearson correlation of $\mathrm{r}=-.571^{*}$ and $p=.000$ which is less than the significant level of 0.01 which means career development is strong negative significant relationship with turnover. In general all five important organizational variables have negative significant relationship with absenteeism and turnover and more strong inversely related with turnover.

Regression analysis of demographic, job and organizational factors with absenteeism and turnover. Table: 4. Regression of demographic, job and organizational factors on absenteeism and turnover

\begin{tabular}{lllllll} 
& \multicolumn{7}{c}{ Absenteeism } & \multicolumn{4}{l}{ Turnover } \\
\cline { 2 - 7 } Causes & $\mathrm{P}$ & $\mathrm{R}$ & $\mathrm{R} 2$ & $\mathrm{P}$ & $\mathrm{R}$ & $\mathrm{R} 2$ \\
Marital status & .004 & .396 & .157 & .000 & .706 & .498 \\
Ege & .022 & .323 & .104 & .002 & 0.433 & 0.187 \\
Working experience & .006 & .386 & .149 & .001 & 0.462 & 0.213 \\
Workload & .029 & 0.308 & 0.095 & .000 & .525 & .276 \\
Working conditions & .000 & .662 & .439 & .000 & .594 & .353 \\
Incentive programs & .017 & .337 & .113 & .000 & .532 & .283 \\
Promotional opportunities & 0.02 & .327 & .107 & .000 & .250 & .063 \\
Managerial style & .040 & .250 & .063 & .000 & .497 & .247 \\
Training and development & .001 & .447 & .199 & .000 & .603 & .364 \\
Career development & .000 & .505 & .255 & 0.00 & .597 & .356 \\
\hline
\end{tabular}

\section{CONCLUSION}

Based on the results of findings the following conclusions were made:

The results revealed that among the demographic factors/variables gender has insignificant correlation with 
absenteeism and turnover. Whereas age, educational level, marital status and experience of medical staffs have a negative correlation with absenteeism and turnover in Arbaminch General Hospital.

Among the job factors, working conditions and workload have positive relationship with absenteeism and turnover. Conversely, routine of work has no relationship with absenteeism and turnover.

The findings also explained that all the organizational factors, incentive programs,/compensation, promotional opportunities, training and development, managerial style, career development have significant negative relationship with dependent variables; absenteeism and turnover.

Absenteeism and turnover of medical staffs have a consequence on the hospital performance. This leads the hospital to lose its reputation the potential customers or patients may turn back towards other hospitals for getting good care.

Absenteeism and turnover of medical staffs have significant impact on the patient care in Arbaminch General Hospital. This means as the medical staffs become absent from their work and leave the organization; the quality of patient care tends to decrease.

Absenteeism and turnover of medical staffs have impact on the morale of the existing staffs. This shows that when the medical staffs do not commit to their work, the other existing staff will be demoralized as they are overloaded. In addition, if the medical staffs leave the hospital the existing/remaining workers feel that they will be demoralized.

\section{Implication of future study}

This study focused on one Governmental hospital. The finding also indicates the causes and consequences of absenteeism and turn over in Hospital. This is difficult to say in every hospital the factors are limited to these. So, the future researchers can conduct the same problems by adding other variables in addition to these explained in this study. In addition, the study dealt with the primary data collected from the respondents. In this case this will help to solve the qualitative data. But it is good to add secondary data especially on the impact of absenteeism and turnover on the hospital performance. This will solve the cost-effectiveness in dealing with absenteeism and turnover problems.

\section{REFERENCES}

Aaron, Cohen and Ronit, Golan. (2007). Predicting absenteeism and turnover intentions by past absenteeism and work attitudes. International Journal of Career.

Albizu-Garca-a CE, Ra-Os R, Juarbe D.and Alegra-an, M. (2004). Provider turnover in public sector managed mental health care. Journal of Behavioral Health Services. V 31(3):255-265. [PubMed: 15263865]

Ahm shamsuzzoh Md. and Rezaul Hasan ,Shumon. (2007). Employee Turnover-a Study of its Causes and Effects to different Industries in Bangladesh. Manufacturing Engineering/ Vyrobne, 2007 - tuke.sk. p 64-66.

Anastasia A. Mallidou, Greta G. Cummings, Carole A. Estabrooks, Phyllis B. Giovannetti(n.d). Causal Relationships between Nurse Specialty Subcultures and Patient Outcomes in Acute Care Hospitals. Canada

Anderson, M.A. \& Halsam, W.B. 1991. How Satisfied Are Nursing Home Staff? American Journal of Nursing Company, 12:85-87

Anderson, RA., Corazzini KN. \& McDaniel RR. (2004). Complexity science and the dynamics of climate and communication: reducing nursing home turnover. Gerontologist, volume 44, page 378-388.

Batt, R. \& Valcour, P. M. (2003). Human resources practices as predictors of work-family outcomes and employee turnover. Industrial Relations, 42(2), 189-220

Beverley Ann, Josias. (2005).The relationship between job satisfaction and absenteeism in a selected field services section within an electricity utility in the Western Cape. Faculty of economic and management sciences .department of industrial psychology of the University of the Western Cape.

Brikend, A. (2011). Job satisfaction: a literature review. Faculty of business and economics, south east European university.makedonia, management research and practice vol. 3 issue 4 (pp: 77-86

Bilgin, Şenel. and Dr. Mine Senel. (2012). The cost of absenteeism and the effect of demographic characteristics and tenure on absenteeism. Interdisciplinary journal of contemporary research in business, VOL 4, NO 5 (p- 1145).

Bingley, P. and Westergaard-Nielsen, N. (2004). Personnel policy and profit. Journal of Business Research.vo 57(5):557-563.

Bilgin Şenel Dr and Mine Şene Dr (2012). The cost of absenteeism and the effect of demographic characteristics and tenure on absenteeism. Interdisciplinary journal of contemporary research in business: Vol 4(5).

Blegen and Mueller, 1987; Buiser, 2000, Blegen and Mueller, 1987, Gillies., 1990. Kramer and Hafner, 1989; Kramer and Schmalenberg, 1988a; 1988b. Aiken, 2002, Aiken., 2008, Blegen., 2001, Blegen., 1998. Mitchell and Jones, 1996.

Brooke, 1986, Hayes et al,. 2006, McBey and Karakowsky .2001, Steers and Rhodes 1978, cited by Aaron Cohen and Ronit Golan (2007). Predicting absenteeism and turnover intentions by past absenteeism and 
work attitudes. International Journal of Career Mana Management: School of Political Science, Division of Public Administration. University of Haifa. Israel, ISSN: 0955-6214.

Bronwyn Anderson. (2009). The relationship between absenteeism and on - site employer -sponsored childcare. UNIVERSITY OF SOUTH AFRICA

Burton, R. 1992. Tackling absenteeism. Nursing Standard, 7(3):37-40.

Cem, Tanovaa.Brook,s C. and Holtomb (2008).Using job embeddedness factors to explain voluntary turnover in four European countries. The International Journal of Human Resource Management. Faculty of Business and Economics, Eastern Mediterranean University: Vol. 19, No. 9, September 2008, (19.9)1553-1568

Creteur M, Pocket Y., Pouplier I., CLOSON MC. (2000). Organizational performance Evaluation of Belgian Hospital. Working paper,

Dana, B. (2005). Taking the measure of quality in LTC. Provider, February, 41-44.

Hart, P. (2003). Patient to nurse staffing ratios: perspective from hospital nurses. AFT Healthcare.

David, R N. Ph.D. and Nancy N, Ph.D. (2001).Performance Measures for Health Care Systems. Commissioned Paper for the Center for Health Management Research: Michigan State University and Virginia Mason Medical Center.

D. Rajan (2013). Afro Asian Journal of Social Sciences. Impact of nurse's turnover on organization performance. Volume 4, No. 4.4 Quarter IV 2013.

Fahad, Abdali. (2011).Impact of Employee Turnover on Sustainable Growth of Organization in Computer Graphics Sector of Karachi, Pakistan. Afro Asian Journal of Social Sciences: Volume 2, No. 2.4 Quarter IV 2011 .ISSN $2229-5313$

Gerber, P.D., Nel, P.S. \& Van Dyk, P.S. (1998). Human Resources Management. Southern Africa: International Thomson Publishers.

Gillies, D.A (1994). Nursing Management: A system approach. Philadelphia: Saunders.

Hacker C.A (1999). The cost of bad hiring decisions and how to avoid them. Boston: St Lusia Press.

Hayes, L. (2006). Nurse turnover: A literature review. International Journal of Nursing Studies, 43, (pp) 237263.

Henry Stanley, k. (2011). Factors affecting voluntary nursing staff turnover in mango hospital. Requirements for the degree of masters of public health. South Africa: university of South Africa supervisor.

Jackson, D. (2003), Taunton, R.L., Hope, K., Woods, C.Q. \& Bott, M.J. (1995). Predictors of absenteeism among hospital staff nurses. Nursing Economics, 13(4):217-229.

John, Sutherland. (2000). “Job-to-job turnover and job to-non- employment movement” Personnel Rev. 31(6): $710-721$

Jama.(2002), Keijsers GJ, Schaufeli WB, LeBlanc PM.(n.d). Performance and burnout in intensive care units. Work Stress 1995; 9:513-27

Laschinger, S., Heather, K. \& Sullivan, D. 1997. The Effect of workplace Empowerment on Staff Nurses Occupational Mental Health and Work Effectiveness. The Journal of Nursing Administration, 27(6):42-50.

Laureen, J. Hayesa, Linda. O'Brien-Pallasa, Christine Duffield, Judith Shamianc,James Buchand, Frances Hughese,f, Heather, K. Spence Laschingerg, Nicola North and Patricia ,W. Stoneh.(2006). Nurse turnover: A literature review. International Journal of Nursing Studies: Vol 43 pp. 237-263.

Lohr, K. \& Schroeder, S. A (1990). A strategy for quality assurance in Medicare New England. Journal of Medicine.vol 322, 707-712.

Lyman W. Porter, Lyman W, Porter and Richard M, Steers (1972). Organizational, work and personal factors in turnover and Absenteeism University, Office of Naval Research, national technical information service, California

Maryland and Aspen, S. (1980). An Investigation of turnover and retention factors of health professional staff within the Eastern Cape department of health. Rhodes university .pp (19-20).

Masibulele Theophilus Mrara. (2010). An investigation of turnover and retention factors of health professional staff within the Eastern Cape department of health. Rhodes University.

Naresh khatri Pawan budhwar Chong tze fern. (N.D).Employee turnover: bad attitude or poor management? Singapore.

Phillips, J. D. 1990. “The price tag on turnover”, Personnel Journal, 69(12):58-61

Pierre de, Wit. (2006). Reasons for absenteeism in the department of defense. Department of people management and development faculty of economic sciences. : Tshwane university of technology.

Pascale Carayon, Ayse P. Gurses (n.d). Nursing Workload and Patient Safety-A Human Factors Engineering Perspective

Pillay, M. (2009) Absenteeism in the Workplace [Online] Available at http://www.britishchamber.co.za/workgroups/BEE/Siyakha\%20\%20AbsenteeismintheWorkplace.[Accesse d 09 Aug 2010

Prado, A. G. \& Chawla, M. 2006. The impact of hospital management reforms on absenteeism in Costa Rica. 
Health and Policy Planning, 21(2):91-100.

Price L and Mueller, C.W (1981a), Professional Turnover: The Case of Nurses, SP Medical and Scientific Books, New York.

Price, and Waterhouse, C. (2007). What works: healing the healthcare staffing shortage. Price Waterhouse Coopers.

Ragani, Singh.(2012). Factors contributing to absenteeism of nurses in primary care centers in the ethekwini municipal district of kwazulu-natal. Stellenbosch University.

Reidenbach, RE. Sandifer-Smallwood, B. (1990). J. HealthCare Market. African Journal of Business Management: Vol.6 (22), pp. 6516-6529.

Renuka, Rathod.and Basavanth, Reddy. Dr (2012).Employee Absenteeism. International Journal of Engineering. And Science: Bangalore. (IJES).Vo (1) P 80-84: ISSN: 2319 - 1813.

Rowland, S. \& Rowland, L. (1993). Nursing administrative handbook.

Rirhandzu norah mongwe. (2007). Student nurses' experiences of the clinical field in the Limpopo province as learning field: A phenomenological study. University of South Africa

Samuel, E.M.and C. O. Ikemefuna. (2012).Job Satisfaction and Employees' Turnover Intentions in total Nigeria plc. In Lagos State: International Journal of Humanities and Social Science. Vol.2 (14).

Shaw, C. (2003). How can hospital performance be measured and monitored? Retrieved from WHO Regional Office for Europe (Health Evidence Network report; http://www.euro.who.int/document/e82975.

Sindiwsa Victoria, M. Werner, January, Steven T. Hunt SPHR, (2009). Staff turnover at selected government hospitals. www.successfactors.com

Staw, B. M. (1980). The consequences of turnover. Journal of Occupational Behavior, 1, 253-273.

Steven, hunt. Ph.D., Sphr (2009). Nursing Turnover: Costs, Causes, \& Solutions. Director of business transformation.

Sullivan, E.J. \& P.J. (1992): Effective management in Nursing. California: Addison Wesley.

Sydney, N. And Royal, A. (1999) Workplace attendance and absenteeism. (Report ISBN no. 0958615721 , A.C.N. 000039 047).145 Macquarie street.

Tetty, W. J. 2005. Staff Retention in African University: Elements of a Sustainable Strategy (On-line). http://siteresources.worldbank.org/INTAFRREGTOPTEIA/Resources/Academic

Retention_Final_pdf [11/12/2009]

Tsegaye, Mada.(2005).Arbaminch hospital key performance indicators (KPI)) report data element input form.( report no 121-53/2005).SNNPRS; Gamo Gofa zone :Arbamnich hospital.

Unruh 2008, Aiken. (2002), Needleman. (2002), Cho et al. (2003), Lang et al. (2004), and Kane. (2007). Nurse staffing: Key to good patient, nurse, and financial outcomes 